\title{
Mechanical properties of coordination polymer-based dietary supplements
}

\author{
Guoqiang Feng ${ }^{1}$, Yongqing Yang ${ }^{2}$, Chunlei $\mathrm{Pei}^{3^{*}}$ and $\mathrm{Wei} \mathrm{Li}^{4^{*}}$
}

In the past two decades, coordination polymers (CPs) have been studied intensively in materials science due to their chemical diversity and unique hybrid nature integrating both the organic and inorganic components at the molecular level [1-3]. Recently, considerable efforts have been dedicated to investigating their physical properties, which include gas adsorption and separation [4], drug delivery [5], catalysis [6], ferromagnetism [7], ferroelectricity and multiferroicity [8]. Despite extensive studies on numerous properties of CPs, there is a major lack of knowledge about their applications as food dietary supplements and additives, which are commonly consumed in our daily life to provide mineral nutrition [9]. In terms of composition, CP-based dietary supplements have better bioactivity and less side-effects than conventional purely inorganic food supplements, and play a significant role in the food and pharmaceutical industry [10]. CP-based supplements and additives cover a wide range of materials, including calcium (e.g., calcium gluconate, calcium aspartate, calcium fumarate), copper (e.g., copper glycinate), magnesium (e.g., magnesium malate), zinc (e.g., zinc glycinate, zinc acetate), iron (e.g., ferrous fumarate), and potassium (e.g., potassium citrate) derivatives $[9,11-15]$.

In the industrial-scale pharmaceutical manufacturing, for molecule drug crystals, the tablet form is often preferred as the dosage form among liquid, soft gel, powder, and capsule [16], because of its excellent product specifications such as long term stability, low cost, good portability, ability to resist tampering, high production throughput, flexibility with a unique product image (shape, size, and color) and easy usage [16-18]. However, the confronting challenge is that the successful development of a tablet dosage form should consider the solubility, stability, bioavailability, and mechanical properties of the product. Fortunately, crystal engineering is widely utilized in designing active pharmaceutical ingredients (APIs) to solve above problems, and it can also be used to tune the mechanical properties such as grindability and tabletability. For example, there are many studies for adopting the optimum measures of constructing tablet product, such as cocrystallization [19-21], hydrates [22,23], salt formation [24] and multicomponent crystals [25].

Notably, one of the significant physicochemical properties of APIs is their mechanical properties (e.g., plasticity and elasticity). During tableting process of pharmaceutical powder, the crystals are milled and compacted, and the elastic and plastic properties during this complex process directly influence the powder tabletability [9,21,25-27]. For example, strong elastic recovery (the extent of slight recover during the decompression and ejection phases) after compression is considered as the main reason of adverse phenomena such as capping or delamination of tablets $[17,18,25]$. Furthermore, a better plasticity (the ability for a material undergoing permanent shape change, local structural distortion and irreversible deformation under the stress) via slipping in a crystal may result in more facile milling and better tabletability, which usually originates from the motions of dislocation along some specific slipped planes $[25,27]$. So it is of fundamental importance to understand the relationship between the crystal structure and mechanical properties of API crystals.

\footnotetext{
${ }^{1}$ Department of Physics and Mechanical \& Electrical Engineering, Hubei University of Education, Wuhan 430205, China

${ }^{2}$ School of Physics, Huazhong University of Science and Technology, Wuhan 430074, China

${ }^{3}$ School of Chemical Engineering and Technology, Tianjin University, Tinanjin 300350, China

${ }^{4}$ School of Materials Science and Engineering \& Tianjin Key Laboratory of Metal and Molecule-Based Material Chemistry, Nankai University, Tianjin 300350, China

* Corresponding authors (emails: wl276@nankai.edu.cn (Li W); chunlei.pei@tju.edu.cn (Pei C))
} 
However, comparing with the common pharmaceutical molecule drug crystals, food dietary supplements CPs present a significant lack of available knowledge on the elastic and plastic properties. Only few systematic studies involving zinc acetate dihydrate, zinc glycinate hydrate and calcium fumarate trihydrate have been investigated in the literatures $[9,14,15]$. It is worth noting that many CPs and coordination complexes (e.g., calcium gluconate [28], vitamin $\mathrm{B}_{6}$ [29] and ferrous fumarate [28,30]) have been served as APIs in tablet form, for example, calcium gluconate $(\mathrm{CHCaO})$ tablet is not only a mineral supplement and medication, but also used as a source of $\mathrm{Ca}^{2+}$ ion to regulate the drug release with the change in the concentration of calcium gluconate in alginate matrix tablets [31]. However, little has been known about the structuremechanical property relationship of these $\mathrm{CP}$ crystals though it is of vice importance for their formulation and tableting, such as understanding the disintegration, dissolution and release $[31,32]$. This perspective highlights the latest advances in mechanical properties of CP-based dietary supplements, and discusses their determining influences in pharmaceutical manufacturing by comparing with small molecule drug crystals and inorganic dietary supplements.

The quantitative characterization of the mechanical properties of crystals can be facilitated by the nanoindentation technique, which has been successfully demonstrated for both metal-organic frameworks and organic crystals (including many small molecular pharmaceuticals such as APIs) [9,20,24,26,27]. Elasticity and plasticity of known CPs can be reflected by conventional mechanical metrics such as Young's modulus $(E)$ and hardness $(H)$. Fig. 1 demonstrates the structures of some selected CP-based food supplements, inorganic dietary supplements and small molecule drug crystals, and their $E$ and $H$ are plotted in Fig. 2.

For inorganic food dietary supplements, the mechanical properties of magnesium oxide ( $\mathrm{MgO}, \mathrm{Fm}-3 \mathrm{~m}$, cubic), zinc oxide ( $\mathrm{ZnO}, P 63 m c$, hexagonal wurtzite structure), and calcium carbonate $\left(\mathrm{CaCO}_{3}, R-3 c\right.$, trigonal, Fig. 1a) crystals have been studied using a nanoindentation technique [33-35]. Caceres et al. [34] reported the $H$ and $E$ of pure $\mathrm{MgO}$ single crystals and for $\mathrm{MgO}$ crystals doped with $\mathrm{H}, \mathrm{Li}, \mathrm{Ni}$ or $\mathrm{Co}$ impurities, subjected to different thermal treatments. The results show that a constant value of $300 \mathrm{GPa}$ for $E$ was obtained in all cases, signifying that the elastic properties are not influenced by impurities or intrinsic defects. Moreover, the pure $\mathrm{MgO}$ crystals have a hardness of 9.2(2) GPa, and the enhancing hardness of doped crystals originated from impurities, point defects, cavities and metallic precipitates, which indicates that impurities and thermally caused intrinsic defects significantly modifies the hardness of $\mathrm{MgO}$ single crystals. Kucheyev et al. [35] reported the deformation behavior of bulk $\mathrm{ZnO}$ single crystals by nanoindentation in combination with atomic force microscopy. Nanoindentation results reveal that plastic deformation has been observed with relatively low loads $(\geqslant 4-13 \mathrm{mN})$ and an $\sim 4.2 \mu \mathrm{m}$ radius spherical indenter, and the average values of the $H$ and $E$ are $\sim 5.0$ and $\sim 111.2 \mathrm{GPa}$, respectively. Remarkably, the elastic-plastic threshold has been found to be dependent on the loading rate, and faster loading can result in larger threshold values, on average. Furthermore, slip has been identified as the major mode of plastic deformation in $\mathrm{ZnO}$, which is responsible for the pop-in events witnessed during loading. In addition, Merkel et al. [33] reported the mechanical properties of calcite $\left(\mathrm{CaCO}_{3}\right)$ by nanoindentation on shell of the rhynchonelliform brachiopod Mergerlia truncate, the $H$ and $E$ are $\sim 4.6$ and $\sim 80 \mathrm{GPa}$ for the calcitic shell of Mergerlia truncate, respectively.

Turning attention to molecular crystals which are often brittle, their mechanical performance in the situation of crystal packing, slip, and defects plays an important role in pharmaceutical manufacturing. Moreover, molecular crystals are usually stabilized by weak interactions, such as hydrogen bonds and van der Waals interactions. As shown in Fig. 2, we plot the data of $E$ and $H$ for small molecule drug crystals, e.g., theophylline-methyl gallate [21], aspirin [36], saccharin [38], sodium saccharin [39], felodipine [37], voriconazole [24], omeprazole [40], sulfa drug [41], curcumin, $L$-alanine and caffeine:4chloro-3-nitrobenzoic acid [21,42,43]. When comparing with the inorganic dietary supplement compounds $(E \sim$ 80-300 $\mathrm{GPa}$ and $\mathrm{H} \sim 5-9 \mathrm{GPa}$ for $\mathrm{MgO}, \mathrm{ZnO}$ and $\mathrm{CaCO}_{3}$ ), the $E$ and $H$ of these drug crystals are significantly lower and the ranges of $E$ and $H$ are $\sim 3.79-25.1 \mathrm{GPa}$ and 0.01-1.14 GPa, respectively, which indicates the mechanical properties of molecular solids significantly differ from these inorganic compounds.

Molecular crystals can also exhibit the characteristic structural anisotropy in mechanical behavior. For example, aspirin is a mild drug that reduces pain and fever. Varughese et al. [36] reported the interaction anisotropy and shear instability of the two polymorphs of aspirin (polymorphs I and II exhibited similar crystal structures). The results of nanoindentation experiment on single crystals show that $\{001\}$ face of polymorphs I is stiffer and harder than $\{10-2\}$ face of polymorphs II, with a difference of $48 \%$ for the elastic moduli and $37 \%$ for the 

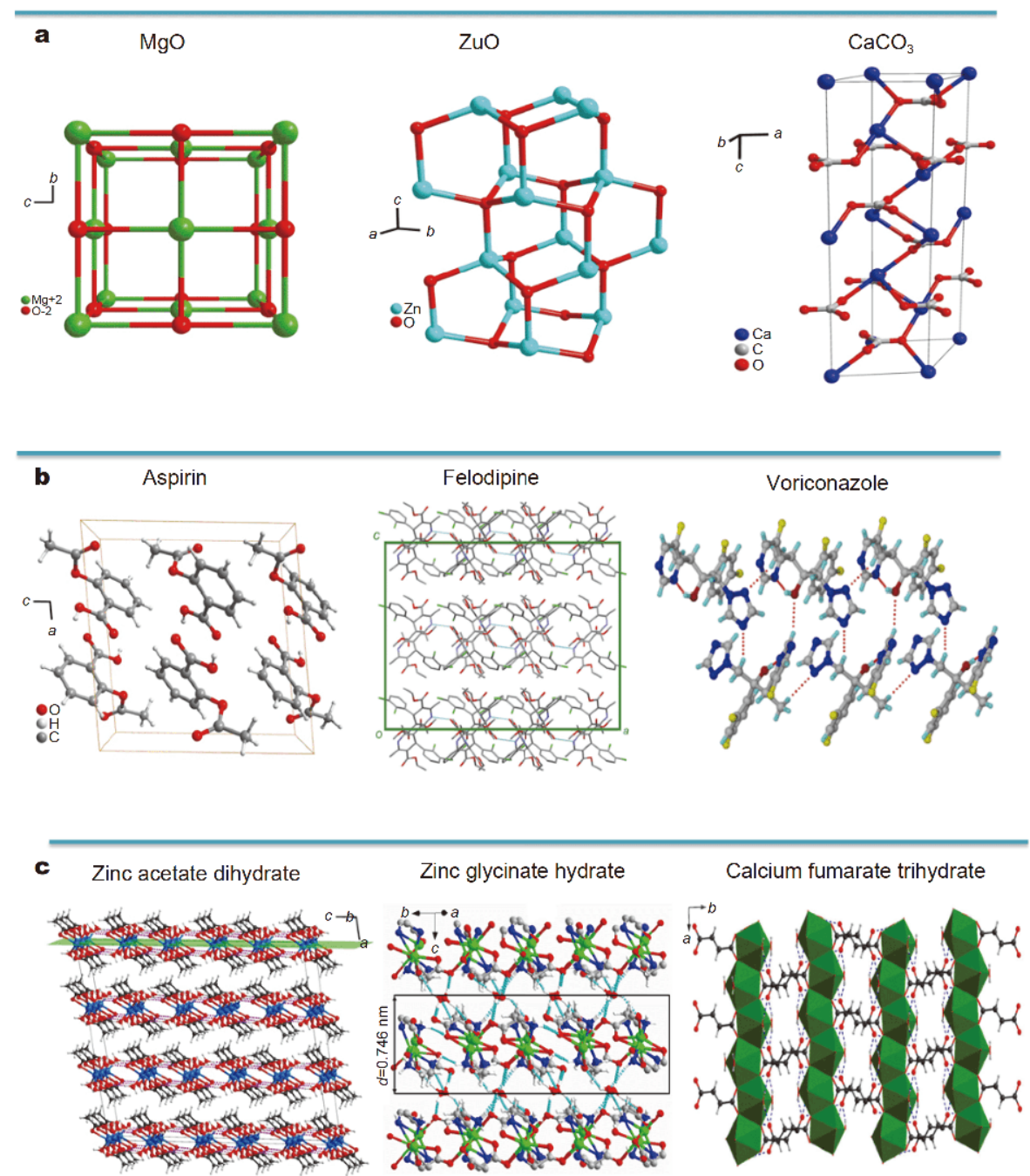

Figure 1 (a) The crystal structures of three inorganic dietary supplements $\left(\mathrm{MgO}, \mathrm{ZnO}\right.$ and $\left.\mathrm{CaCO}_{3}\right)$ [33-35]. (b) The typical small molecule drug crystals (aspirin-polymorphs I, felodipine-form II and voriconazole) [36]. Reproduced with permission from Ref. [37], Copyright 2014, Wiley-VCH and Ref. [24], Copyright 2015, American Chemical Society. (c) Zinc and calcium dietary supplements (zinc acetate dehydrate, zinc glycinate hydrate and calcium fumarate trihydrate) [14,15]. Reproduced with permission from Ref. [9], Copyright 2015, ACS.

hardness indices for indentation along the potential shearing direction, and slip in II occurs more readily for nanoindentation on $\{10-2\}$ face of II compared with $\{001\}$ of I, which indicates plastic deformation occurs via slip. Additionally, they also found that the stress-induced solid-state II $\rightarrow$ I transformation can be fetched rapidly by mechanical milling, and proceed via a slip mechanism. On the basis of the earlier work on aspirin, Mishra et al. [37] further reported the other intergrowth polymorphism crystal, API felodipine (form II, including two different unit cells), confirmed that this microstructure can lead to a clear bimodal response to nanoindentation on the $\{100\}$ face of form II, but the other indented faces of forms I and III, including the $\{001\}$ face of form II, only showed a standard unimodal response, and the variances of $E$ and $H$ were comparable to the variances obtained for the unimodal indents on all of the other crystal forms, which indicated that these crystals represented distinct, well-defined responses. Moreover, Mishra et al. also found that the response labelled $\{100\}_{(1)}$ was harder and stiffer than $\{100\}_{(2)}$ on the intergrowth polymorphism crystal, demonstrating distinct properties for two polymorphic forms within the same crystal. API crystals are often tuned to improve their mechanical properties for a better manufacturability. A typical example is voriconazole (VOR) crystal, an antifungal drug, which is too soft for tableting and compacting, so crystal engineering is used to make co-crystals and salts with modified me- 


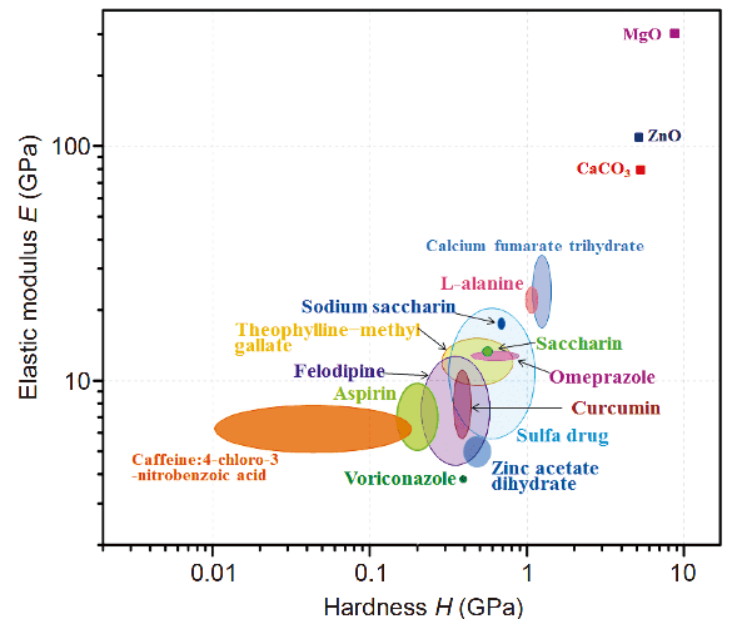

Figure 2 Overview of $E$ vs. $H$ plots of CPs, several well-known inorganic food dietary supplements and small molecule drug crystals $(x$ and $y$-axes are in $\log$ scale). Among these CPs, $E$ and $H$ lie in the ranges of about 4.3-33.4 GPa and 0.01-1.36 GPa, respectively. Comparing with inorganic compounds, such as $\mathrm{MgO}(E \sim 300 \mathrm{GPa}$ and $H \sim 9 \mathrm{GPa}$, Ref. [34]), $\mathrm{ZnO}(E \sim 111.2 \mathrm{GPa}$ and $H \sim 5 \mathrm{GPa}$, Ref. [35] $)$ and $\mathrm{CaCO}_{3}(E$ $\sim 80 \mathrm{GPa}$ and $H \sim 5 \mathrm{GPa}$, Ref. [33]), theses $\mathrm{CPs}$ are much softer and possess more excellent flexibility.

chanical properties. Sanphui et al. [24] reported the tuning mechanical properties of VOR salts (VOR-HCl (1:2), VOR-OXA1 (1:1.5), VOR-OXA2 (1:1)) and cocrystals (VOR-FUM (1:1), VOR-PHB (1:1), VOR-PAB (1:1)) characterized by single crystal X-ray diffraction and nanoindentation. The results show that the salts exhibit better hardness than the drug and cocrystals in the order salts $>>$ drug $>>$ co-crystals. Comparing with drug and co-crystals of VOR, the hardness property of the salts is explained by the reason of stronger ionic interactions, other noncovalent interactions, and lack of slip planes. The presence of a critical number of slip planes and a smaller number of intermolecular interactions make cocrystals softer than VOR. Linked to VOR drug, the API paracetamol (pca) shows improved mechanical properties via cocrystal formation. Karki et al. [19] reported the compression properties of four cocrystals, (pca).(oxa), (pca).(thp), (pca) $)_{2} \cdot\left(\right.$ nap), and (pca).(phe) ${ }_{2}$ (oxalic acid, oxa; theobromine, thb; naphthalene, nap; phenazine, phe), and the comparison of tensile strengths measured for the resulting tablets gave the ranking in the order: (pca). (oxa) $<($ pca $) \cdot(\text { phe })_{2}<(\text { pca })_{2} \cdot($ nap $)<($ pca $) \cdot($ thp $)$, as shown in Fig. 3. Crystal structure analysis confirmed that cocrystals of (pca).(oxa), (pca).(thp), and (pca) $)_{2}$ (nap) have layered structures, which can enhance the ability to form tablets. Interestingly, (pca).(oxa) and (pca).(thp) have strong hydrogen bonds between the APIs and co- crystal formers, However, the structure of $(\mathrm{pca})_{2} \cdot($ nap) shows significant difference, i.e., the layers in this cocrystal are connected by weak $\mathrm{C}-\mathrm{H} \cdots \pi$ and $\pi \cdots \pi$ interactions. Moreover, the non-layered $(\mathrm{pca}) \cdot(\mathrm{phe})_{2}$ is composed of finite Z-shaped assemblies held together by $\mathrm{O}-\mathrm{H} \cdot \cdots \mathrm{N}$ and $\mathrm{N}-\mathrm{H} \cdots \mathrm{N}$ hydrogen bonds. And the calculations indicate (pca).(oxa) has the least compliance to shear stress, which gives relevant tablets with the lowest tensile strength. Furthermore, Ainurofiq et al. [25] reported a multicomponent crystal of desloratadine (DES-BA, a salt crystal) with improved mechanical properties (desloratadine is an anti-histamine drug, BA is benzoic acid). The compaction measurements show that the tablets' tensile strength of DES-BA $(>2 \mathrm{MPa})$ has been attained at compaction pressures $>200 \mathrm{MPa}$, which is higher than DES $(<1 \mathrm{MPa})$ at pressures $<150 \mathrm{MPa}$ (the proposed minimum tensile strength is $2 \mathrm{MPa}$ for ensuring integrity of a pharmaceutical tablet). And a tendency of capping is observed in the DES tablets with the pressure increasing higher than $250 \mathrm{MPa}$, but DES-BA could be made into good tablets up to $350 \mathrm{MPa}$ (neither capping nor lamination tendency was observed), as shown in Fig. 3f, g. Their studies show this multicomponent crystal has better tabletability and plasticity profiles than the parent drug, which is attributed to the presence of a layered structure and slip planes.

In contrast to the research of mechanical properties in organic pharmaceutical molecules, there are very few reports on the fundamental mechanical properties of $\mathrm{CP}$ based food supplements and additives. Sun et al. [9] reported the mechanical properties of calcium fumarate trihydrate $\left(\mathrm{Ca}\left(\mathrm{C}_{4} \mathrm{H}_{2} \mathrm{O}_{4}\right) \cdot 3 \mathrm{H}_{2} \mathrm{O}\right.$, one dimensional (1D) coordination polymer shown in Fig. 1c, a calcium source for food and beverage) using nanoindentation and highpressure X-ray diffraction. The ranges of $E, H$, yield stress and creep behavior are 16.7-33.4 GPa, $1.05-1.36 \mathrm{GPa}$, $0.70-0.90 \mathrm{GPa}$ and $0.8-5.8 \mathrm{~nm} \mathrm{~s}^{-1}$, respectively, which are influenced by the directionality of the inorganic $\mathrm{Ca}-\mathrm{O}-\mathrm{Ca}$ linkages, $\mathrm{O}-\mathrm{H} . . \mathrm{O}$ hydrogen bonding and the orientation of the fumarate ligands. Notably, the $E$ and $H$ of calcium fumarate trihydrate are significantly lower than the values for inorganic food supplements, while being much higher than those of organic pharmaceutical molecules, as shown in Fig. 2. Moreover, the results of high-pressure single-crystal X-ray diffraction experiments reveal a bulk modulus of $20 \mathrm{GPa}$, which indicates it is elastic recovery intermediate between organic pharmaceutical $(\sim 13 \mathrm{GPa})$ crystals and inorganic dietary supplements (MgO, $73 \mathrm{GPa} ; \mathrm{CaCO}_{3}, \sim 160 \mathrm{GPa}$ ) [9].

Feng et al. [15] first reported the negative area com- 

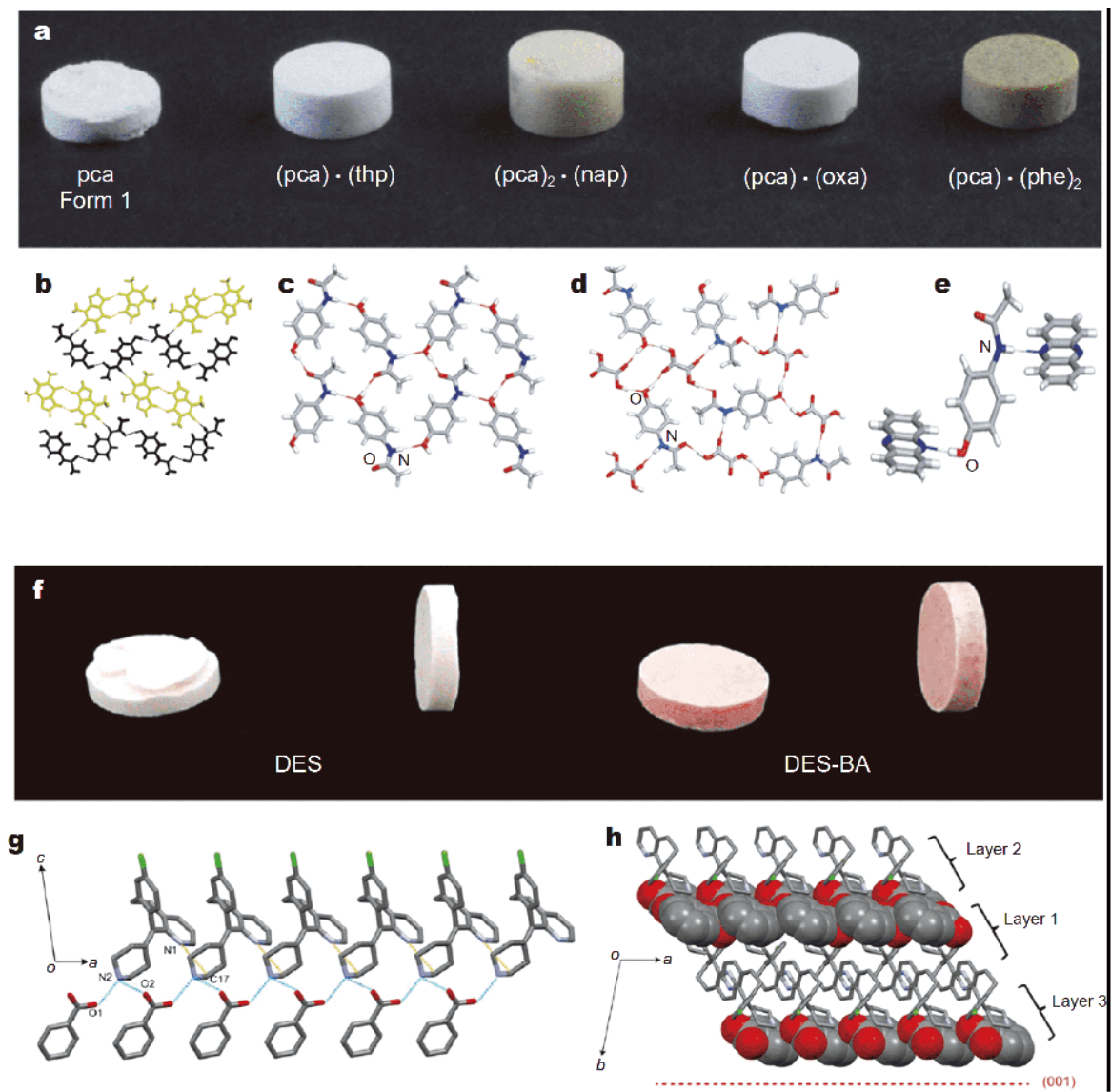

Figure 3 (a) The tablets resulting from compression experiments in pca form I and the four derived cocrystals. (b, d) The hydrogen-bonded layer in (pca).(oxa) and (pca).(thp). (c) A single layer of pca in (pca) $)_{2}$ (nap). (e) Molecular assembly in (pca).(phe) $)_{2}$. Reproduced with permission from Ref. [19], Copyright 2014, Wiley-VCH. (f) Tablets of DES and DES-BA at a compaction pressure of $350 \mathrm{MPa}$. (g) A layered structure constructed by a 1D hydrogen bonding chain between DES-BA pairs. (h) The packing layers along the $c$ axis enabled slip planes parallel to (001). DES and BA are plotted in capped stick and spacefill types, respectively. Reproduced with permission from Ref. [25], Copyright 2018, Elsevier.

pressibility (NAC) of zinc acetate dihydrate $\left(\mathrm{Zn}\left(\mathrm{CH}_{3}-\right.\right.$ $\mathrm{COO})_{2} \cdot 2 \mathrm{H}_{2} \mathrm{O}$, food supplement and drug for treating cold) using high-pressure synchrotron powder $\mathrm{X}$-ray diffraction (HP-PXRD). $\mathrm{Zn}\left(\mathrm{CH}_{3} \mathrm{COO}\right)_{2} \cdot 2 \mathrm{H}_{2} \mathrm{O}$ crystallizes in the monoclinic space group and shows a hydrogenbonded layered supramolecular architecture (Fig. 1c). The results of HP-PXRD reveal the large NAC $(K=$ -8.1(8) $\mathrm{TPa}^{-1}$ ) over a wide pressure range of $0.15-$ $4.44 \mathrm{GPa}$, which ranks the third largest in all hitherto known 8 NAC materials, and the largest if excluding those with phase transitions and metastable high-pressure NAC. Interestingly, the microscopic mechanism of the NAC behavior arises from the complex cooperation of intra-layer coordination and hydrogen-bonding interactions, and inter-layer van der Waals forces. In addition, the isothermal bulk modulus of 20(2) GPa is comparable to that of calcium fumarate trihydrate. Furthermore, the average values of $E$ and $H$ values are 4.3(2) and 0.37(2) GPa for (100) face, and 5.8(3) and 0.58(5) GPa for (001) face, respectively. The $E$ modulus shows medium anisotropy with $E_{(001)} / E_{(100)}=1.35$ in elastic deformation, while the hardness exhibits large anisotropy with $H_{(001)}$ ' $H_{(100)}=1.57$ in plastic deformation. The difference $(26 \%)$ in the elastic moduli for the crystal faces indicates possible dissimilarities in the interaction features. And the much larger anisotropy in hardness (36\%) suggests significant differences in the micro-mechanisms of plasticity. Therefore, the $H$ and $E$ values obtained on the two different natural facets for the (100) and (001) faces manifest significant mechanical anisotropy of $\mathrm{Zn}\left(\mathrm{CH}_{3} \mathrm{COO}\right)_{2} \cdot 2 \mathrm{H}_{2} \mathrm{O}$.

Azeem et al. [14] recently reported the elastic and hydrostatic behaviour of a zinc dietary supplement, zinc glycinate gydrate $\left(\mathrm{Zn}\left[\mathrm{O}_{2} \mathrm{CCH}_{2} \mathrm{NH}_{2}\right]_{2} \cdot \mathrm{H}_{2} \mathrm{O}\right.$, a pseudo $2 \mathrm{D}$ 
structure with monoclinic space group), via the density functional theory (DFT) calculations and HP-PXRD. The range of $E$ is in 13.84-36.11 GPa by the DFT calculations, indicating significant elastic anisotropy, and the $B / G$ ratios of 1.30-3.83 ( $B$ and $G$ are bulk modulus and shear modulus, respectively) reveal the crystal could be brittle under uniaxial stress according to the Pugh's criterion. Furthermore, the bulk modulus is $\sim 31 \mathrm{GPa}$, which is slightly higher than that of $\mathrm{Zn}\left(\mathrm{CH}_{3} \mathrm{COO}\right)_{2} \cdot 2 \mathrm{H}_{2} \mathrm{O}$ and lies in the middle of the values between inorganic dietary supplements and organic pharmaceutical crystals.

The manufacturing process of tablets can vary with the product requirement but typically includes milling, blending, granulation and tableting, as shown in Fig. 4, which can be significantly influenced by the crystalline structure and mechanical properties of API and excipient particles. Therefore, it is necessary to clarify the influence factors of crystal structure and material properties on the formulation and manufacture of pharmaceutical tablets. For the milling process, the brittleness of crystals plays a significant role. If a material shows a good deformability, it may hinder the milling process. For example, soft voriconazole becomes paste-like upon grinding, which makes it difficult to mill, but the hard sildenafil citrate is easier to handle [24]. Blending and granulation processes are also highly influenced by crystal morphology, mechanical and surface properties. The segregation in mixtures (e.g., API and excipient) is commonly induced by the difference of particles size, density and surface energy $[44,45]$. The segregation of API and excipient can result in undesired product qualities, such as over- or underdosing. The tabletability of the bulk powder is significantly determined by the crystal plasticity and elasticity. The plasticity of $\mathrm{CP}$ crystals can be influenced by several crystal features, such as crystal packing, slip, dislocation motion, twinning, kinking, and perturbation of lattice stability. For example, introducing more slip planes is a valid strategy for plasticity enhancement in crystal engineering, which facilitates the compaction of powders with poor tabletability [20]. And the motions of intrinsic dislocations can contribute to crystal plasticity, which generally weakens the lattice and enables plastic deformation under neglecting work hardening. The crystal elasticity can cause the elastic recovery of tablets during decompression. A strong elastic recovery can even break the tablet and causes capping or delamination after tablet ejection [46]. Therefore, both high elasticity and low plasticity of crystal can lead to poor tableting performance. On the other hand, the mechanical operations on the crystal particles during the manufacturing process can

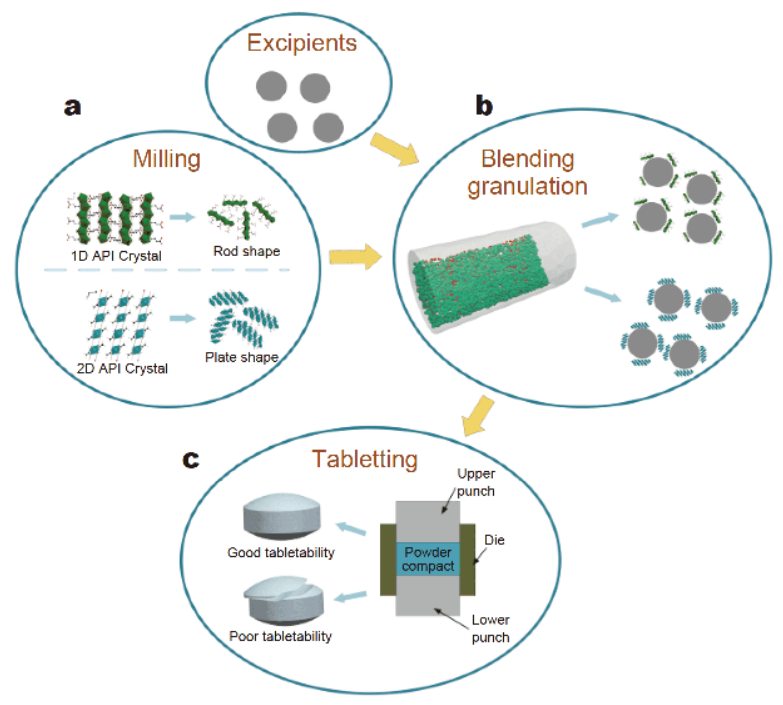

Figure 4 The manufacturing process scheme of typical pharmaceutical tablets. (a) 1D and 2D APIs are milled to form nanorod and nanosheet shape powders, respectively. (b) Blending and granulation for the mix of the APIs powder and excipients is performed. (c) A standard in-die compaction process.

change the properties of the particles. Notably, the phase transitions can appear among APIs during production processes (e.g., milling, handling, and tableting), which further results in the rearrangement of intermolecular interactions and local molecular movements under mechanical loading [47]. For example, in the two co-crystal polymorphs of caffeine:4-chloro-3-nitrobenzoic acid (Form I and Form II), Form I is more brittle and harder than Form II, and can convert readily to Form II upon mechanical grinding [21]. Furthermore, various manufacturing operations may have different requirements of crystal properties, such as the crystal plasticity for milling and tableting as discussed above. Therefore, it is of fundamental importance to properly control and optimize the crystal properties for further manufacturing operations.

In summary, the mechanical properties are critical in the applications of CP crystals, especially in pharmaceutical manufacturing. Compared with other research of small molecule drug crystals, it is vital to draw the interrelations between the material properties and the underlying crystal structures of CP-based supplements and additives in the context of crystal engineering. However, systematic investigations and quantitative understanding of the mechanical properties at the molecular level remains rare, which may be ascribed to the difficulty in preparing crystals, the absence of suitable characterization techniques, and the complex nature of the crystal 
structures themselves. Thus, it is still a key challenge to establish correlations between crystal structure and mechanical response for advancement in this area.

\section{Received 1 September 2019; accepted 4 September 2019; published online 17 September 2019}

1 Rao CNR, Cheetham AK, Thirumurugan A. Hybrid inorganicorganic materials: a new family in condensed matter physics. J Phys-Condens Matter, 2008, 20: 083202

2 Cheetham AK, Rao CNR. There's room in the middle. Science, 2007, 318: 58-59

3 Cheetham AK, Rao CNR, Feller RK. Structural diversity and chemical trends in hybrid inorganic-organic framework materials. Chem Commun, 2006, 216: 4780-4795

4 Li JR, Kuppler RJ, Zhou HC. Selective gas adsorption and separation in metal-organic frameworks. Chem Soc Rev, 2009, 38: 1477

5 Horcajada P, Gref R, Baati T, et al. Metal-organic frameworks in biomedicine. Chem Rev, 2011, 112: 1232-1268

6 Lee JY, Farha OK, Roberts J, et al. Metal-organic framework materials as catalysts. Chem Soc Rev, 2009, 38: 1450-1459

7 Weng DF, Wang ZM, Gao S. Framework-structured weak ferromagnets. Chem Soc Rev, 2011, 40: 3157-3181

8 Jain P, Ramachandran V, Clark RJ, et al. Multiferroic behavior associated with an order-disorder hydrogen bonding transition in metal-organic frameworks (MOFs) with the perovskite $\mathrm{ABX}_{3}$ architecture. J Am Chem Soc, 2009, 131: 13625-13627

9 Sun S, Henke S, Wharmby MT, et al. Mechanical properties of a calcium dietary supplement, calcium fumarate trihydrate. Inorg Chem, 2015, 54: 11186-11192

10 Institute of Medicine. Dietary Reference Intakes: For Calcium, Phosphorus, Magnesium, Vitamin D, and Fluoride. Washington, DC: National Academy Press, 1997

11 Straub DA. Calcium supplementation in clinical practice: a review of forms, doses, and indications. Nutr Clin Pract, 2007, 22: 286296

12 Jesserer H. Therapie der Hypocalcämie. Dtsch med Wochenschr, 1967, 92: 1776-1777

13 European Food Safety Authority. Scientific Opinion of the Panel on food additives, flavourings, processing aids and materials in contact with food (AFC) on a request from the Commission on magnesium aspartate, potassium aspartate, magnesium potassium aspartate, calcium aspartate, zinc aspartate, and copper aspartate added for nutritional purposes to food supplements. EFSA J, 2008, 883: 23

14 Azeem M, Asif M, Gui D, et al. Elastic and hydrostatic behaviour of a zinc dietary supplement, zinc glycinate hydrate. RSC Adv, 2019, 9: 13153-13158

15 Feng GQ, Zhang WX, Dong LY, et al. Negative area compressibility of a hydrogen-bonded two-dimensional material. Chem Sci, 2019, 10: 1309-1315

16 Perumalla SR, Sun CC. Enabling tablet product development of 5fluorocytosine through integrated crystal and particle engineering. J Pharm Sci, 2014, 103: 1126-1132

17 Han LH, Elliott JA, Bentham AC, et al. A modified Drucker-Prager Cap model for die compaction simulation of pharmaceutical powders. Int J Solids Struct, 2008, 45: 3088-3106

18 Mazel V, Busignies V, Diarra H, et al. On the links between elastic constants and effective elastic behavior of pharmaceutical compacts: importance of Poisson's ratio and use of bulk modulus. J Pharmaceutical Sci, 2013, 102: 4009-4014

19 Karki S, Friščić T, Fábián L, et al. Improving mechanical properties of crystalline solids by cocrystal formation: new compressible forms of paracetamol. Adv Mater, 2009, 21: 3905-3909

20 Chattoraj S, Shi L, Sun CC. Understanding the relationship between crystal structure, plasticity and compaction behaviour of theophylline, methyl gallate, and their $1: 1$ co-crystal. CrystEngComm, 2010, 12: 2466

21 Ghosh S, Mondal A, Kiran MSRN, et al. The role of weak interactions in the phase transition and distinct mechanical behavior of two structurally similar caffeine co-crystal polymorphs studied by nanoindentation. Cryst Growth Des, 2013, 13: 4435-4441

22 Chang SY, Sun CC. Superior plasticity and tabletability of theophylline monohydrate. Mol Pharm, 2017, 14: 2047-2055

23 Sun CC, Grant DJW. Improved tableting properties of $p$-hydroxybenzoic acid by water of crystallization: a molecular insight. Pharm Res, 2004, 21: 382-386

24 Sanphui P, Mishra MK, Ramamurty U, et al. Tuning mechanical properties of pharmaceutical crystals with multicomponent crystals: voriconazole as a case study. Mol Pharm, 2015, 12: 889-897

25 Ainurofiq A, Mauludin R, Mudhakir D, et al. Improving mechanical properties of desloratadine via multicomponent crystal formation. Eur J Pharmaceutical Sci, 2018, 111: 65-72

26 Varughese S, Kiran MSRN, Ramamurty U, et al. Nanoindentation in crystal engineering: quantifying mechanical properties of molecular crystals. Angew Chem Int Ed, 2013, 52: 2701-2712

27 Ji LJ, Sun SJ, Qin Y, et al. Mechanical properties of hybrid organicinorganic perovskites. Coord Chem Rev, 2019, 391: 15-29

28 Niazi SK. Handbook of Pharmaceutical Manufacturing Formulations Compressed Solid Products. Deerfield: Pharmaceutical Scientist, Inc., 2009

29 Chamayou AC, Neelakantan MA, Thalamuthu S, et al. The first vitamin $\mathrm{B}_{6}$ zinc complex, pyridoxinato-zinc acetate: A $1 \mathrm{D}$ coordination polymer with polar packing through strong inter-chain hydrogen bonding. Inorg Chim Acta, 2011, 365: 447-450

30 Sultana K, Hassan N, Shifa khan M, et al. Formulation of ferrous fumarate (combination) tablets by using a direct-compression method. Ind J Sci Technol, 2010, 3: 994-1000

31 Mandal S, Basu SK, Sa B. Sustained release of a water-soluble drug from alginate matrix tablets prepared by wet granulation method. AAPS PharmSciTech, 2009, 10: 1348-1356

32 Moosa RM, Choonara YE, du Toit LC, et al. A review of topically administered mini-tablets for drug delivery to the anterior segment of the eye. J Pharm Pharmacol, 2013, 66: 490-506

33 Merkel C, Deuschle J, Griesshaber E, et al. Mechanical properties of modern calcite-(Mergerlia truncata) and phosphate-shelled brachiopods (Discradisca stella and Lingula anatina) determined by nanoindentation. J Struct Biol, 2009, 168: 396-408

34 Cáceres D, Vergara I, González R, et al. Hardness and elastic modulus from nanoindentations in nominally pure and doped MgO single crystals. Philos Mag A, 2002, 82: 1159-1171

35 Kucheyev SO, Bradby JE, Williams JS, et al. Mechanical deformation of single-crystal ZnO. Appl Phys Lett, 2002, 80: 956-958

36 Varughese S, Kiran MSRN, Solanko KA, et al. Interaction anisotropy and shear instability of aspirin polymorphs established by nanoindentation. Chem Sci, 2011, 2: 2236-2242

37 Mishra MK, Desiraju GR, Ramamurty U, et al. Studying microstructure in molecular crystals with nanoindentation: intergrowth 
polymorphism in felodipine. Angew Chem Int Ed, 2014, 53: 13102-13105

38 Kiran MSRN, Varughese S, Reddy CM, et al. Mechanical anisotropy in crystalline saccharin: nanoindentation studies. Cryst Growth Des, 2010, 10: 4650-4655

39 Kiran MSRN, Varughese S, Ramamurty U, et al. Effect of dehydration on the mechanical properties of sodium saccharin dihydrate probed with nanoindentation. CrystEngComm, 2012, 14: 2489-2493

40 Mishra MK, Ramamurty U, Desiraju GR. Solid solution hardening of molecular crystals: tautomeric polymorphs of omeprazole. J Am Chem Soc, 2015, 137: 1794-1797

41 SeethaLekshmi S, Kiran MSRN, Ramamurty U, et al. Molecular basis for the mechanical response of sulfa drug crystals. Chem Eur J, 2019, 25: 526-537

42 Mishra MK, Sanphui P, Ramamurty U, et al. Solubility-hardness correlation in molecular crystals: curcumin and sulfathiazole polymorphs. Cryst Growth Des, 2014, 14: 3054-3061

43 Mohamed RM, Mishra MK, AL-Harbi LM, et al. Anisotropy in the mechanical properties of organic crystals: temperature dependence. RSC Adv, 2015, 5: 64156-64162

44 Möbius ME, Lauderdale BE, Nagel SR, et al. Size separation of granular particles. Nature, 2001, 414: 270

45 Alizadeh M, Asachi M, Ghadiri M, et al. A methodology for calibration of DEM input parameters in simulation of segregation of powder mixtures, a special focus on adhesion. Powder Tech, 2018, 339: 789-800

46 Wu CY, Ruddy OM, Bentham AC, et al. Modelling the mechanical behaviour of pharmaceutical powders during compaction. Powder Tech, 2005, 152: 107-117

47 Willart JF, Descamps M. Solid state amorphization of pharmaceuticals. Mol Pharm, 2008, 5: 905-920

Acknowledgements This work is financially supported by the National Natural Science Foundation of China (21571072).

Author contributions Feng GQ, Pei CL and Li W wrote the paper. All authors contributed to the general discussion.

Conflict of interest The authors declare that they have no conflicts of interest.

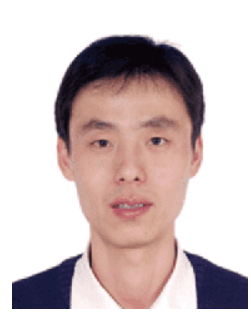

Wei Li obtained his PhD in 2008 from Fujian Institute of Research on the Structure of Matter, Chinese Academy of Sciences. After a postdoctoral training at the University of Cambridge during 2009-2014, he took a professor position in the School of Physics at Huazhong University of Science and Technology in March 2015. In September 2018, he moved to the School of Materials Science and Engineering, Nankai Univeristy. His research focuses on the materials physics and chemistry of coordination polymers and hybrid organic-inorganic perovskites.

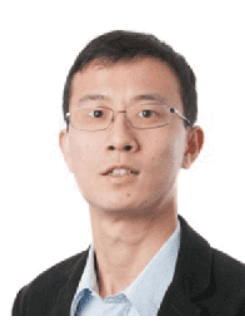

Chunlei Pei is currently an Associate Professor at the School of Chemical Engineering and Technology, Tianjin University. He received his BEng (2006) from Chongqing University and $\mathrm{PhD}$ (2014) from the University of Birmingham. In 2014, he worked as a project officer for a European project-IPROCOM in the University of Surrey. From 2014 to 2018, he worked as a Post-Doctoral Research Associate in the Department of Material Science and Metallurgy, University of Cambridge. Dr. Pei has research interests in powder and multi-phase technologies, using numerical methods and experimental characterization methods, for applications in heterogeneous catalysis, pharmaceutical engineering and relevant chemical engineering areas.

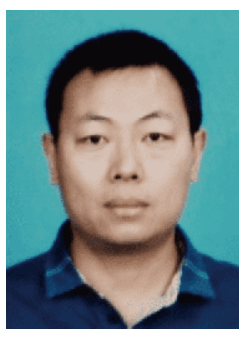

Guoqiang Feng obtained his Master's degree and $\mathrm{PhD}$ from Huazhong University of Science and Technology in 2006 and 2016, respectively. His current research interest is the mechanical properties of hybrid inorganic-organic framework materials.
配位聚合物基膉食补充剂的力学性质研究

冯国强, 杨永青 ${ }^{2}$, 裴春雷 ${ }^{3 *}$, 李伟 ${ }^{4^{*}}$

摘要 由于温和的口服性能和良好的生物兼容性, 配位聚合物基膳 食补充剂一直在市场上广受欢迎. 这类膳食补充剂通常都是以片 剂的形式销售, 其片剂的加工和制造过程与其力学性质密切相关. 本文系统总结了配位聚合物膳食补充剂的晶体结构与力学性质之 间的内在关系, 并与小分子药物晶体和无机膳食补充剂进行比较, 为其片剂加工制造过程提供参考. 